\title{
Chair's note: moving forwards amidst the British International Research Institutes (BIRI) of the British Academy
}

\begin{abstract}
This third Chair's note on the society's activities outlines the wider context of The Society for Libyan Studies within the British Academy's British International Research Institutes (BIRI), and recent developments within this collaboration. The BIRI comprises seven units that are part-funded by the British Academy and that are spread across Southern Europe, Africa and the Middle East. This note outlines the BIRI briefly, and also describes the recent developments that have seen the BIRI begin to explore how they might coordinate their work and their futures more coherently. The BIRI context is key to SLS's future and this note therefore outlines these recent developments.
\end{abstract}

\section{The context of the Society for Libyan Studies}

The Society for Libyan Studies (SLS) receives the bulk of its funding from the British Academy (BA). In turn, this British Academy funding originates from the Government's Department for Business, Energy and Industrial Strategy (BEIS). As such, the British Academy and, by extension, SLS and the other British International Research Institutes (BIRI) are embedded in wider national research funding agendas and initiatives. This context means that the SLS's funding, and the roles expected of us by BEIS and the BA, can shift and change as events unfold. This has become more apparent of late - especially as the British government prepares for possible Brexit scenarios and a re-engineering of Britain's overseas research representation and capacity. In response the BIRI have begun to explore their mutual interests and the potential for closer collaboration in this fast-emerging context. This note outlines this developing situation and some of its potential consequences for SLS.

The British International Research Institutes are organisations that support research plus outreach and engagement agendas in regions across Southern Europe, North and East Africa, and the Middle East. They are each autonomous bodies (and often 
constituted as charities), but all have a key income stream from the British Academy to support research in the humanities and social sciences that addresses their specialist regions. Most of the BIRI support academic staff who undertake research themselves, and all have competitive funding programmes that enable the research of other scholars. Many BIRI have premises that can accommodate their grant awardees and visiting researchers. The majority also offer research facilities including specialist libraries, collections and archives. Some provide equipment and laboratories, and all offer local advice and introductions. Each BIRI publishes a longstanding scholarly journal (and some publish two). All host public outreach and events programmes in the UK and overseas. As such, and taken together, they constitute a unique element of Britain's overseas research infrastructure.

The seven core BIRI are listed in order of their foundation. They are:

- The British School at Athens (BSA) was founded in 1886 and has a remit that stretches across Greece and the Ancient Greek World around the Eastern Mediterranean.

- The British School at Rome (BSR) originated in 1901 and developed a scope that covered Italy, the Classical Roman Empire, and the Mediterranean.

- The Council for British Research in the Levant (CBRL) incorporates the British School of Archaeology in Jerusalem, founded in 1919 and later named the Kenyon Institute, and the British Institute at Amman for Archaeology and History, established in 1978. CBRL maintains bases in Amman and Jerusalem and covers Jordan, Palestine, Israel, Syria, Lebanon and Cyprus.

- The British Institute at Ankara (BIA) originates from 1948 and supports research and engagement throughout the region centred upon modern Turkey and the Black Sea. 
- The British Institute in Eastern Africa (BIEA), is based in Nairobi and was founded in 1960. It funds and facilitates research and engagement activities in Eastern Africa and other regions across Sub-Saharan Africa.

- The British Institute of Persian Studies (BIPS) originated in 1961 and is based in Tehran. It studies the regions centred around contemporary Iran and the wider Persianate world, including Iran, Afghanistan, Transcaucasia, Iraq, the Persian Gulf littoral, and central and South Asia.

- The Society for Libyan Studies (SLS) was established in 1969. It is the smallest BIRI and has never had a base in Libya due to the political contexts of the last 50 years in that country.

Finally, The British Institute for the Study of Iraq (BISI) was formed in 1932 as the British School of Archaeology in Iraq. It is affiliated to the British Academy and is currently being drawn more closely towards the BIRI collective. Like the SLS it is exiled from its research field - having left Iraq in 1990 due to the conflict between the UK and Iraq. It too supports research in the humanities and social sciences.

The BIRI vary in size. The British School at Rome is the largest, with over 30 staff, significant income from the $B A$, plus various bequests and other activities at their large building in Rome. The institutes in Athens, in Amman, in Ankara and in East Africa follow (if ranked in order of British Academy funding). The Institute for Persian Studies and our Society for Libyan Studies are the smallest units. The SLS has two part time staff summing less than one full time employee. We have no physical base besides our archive (housed generously at the University of Leicester) and our library (also hosted kindly in London's School of Oriental and African Studies). As the smallest BIRI within this wider network, it makes clear sense for the SLS to embed firmly within the BIRI.

As may be clear, late nineteenth and early twentieth century British archaeologists and ancient historians, with their interests in ancient civilisations, informed the 
origins of these organisations. The geopolitical reach of British imperialism, and British economic interests, also shaped their development. In our twenty-first century, therefore, the BIRI represent a longstanding and entrenched British research engagement with these world regions and there is plentiful evidence of the contributions to wider research and understanding that these units have generated. The SLS, for example, has a long history of funding field research in Libya that has radically transformed how we understand prehistoric and ancient North Africa. We also support research on the modern period, including recent work on transMediterranean migration via Libya, and the illegal trade in antiquities looted from Libyan conflict zones. Some of our current activities and funded-research therefore stretch beyond research debates and inform contemporary political agendas and current affairs. British Academy funding supports all of this research.

\section{Future contexts for the Society for Libyan studies?}

When I became Chair of the society in late 2016 our future looked unsettled due to debates within the British Academy that questioned the value of the BIRI. There was discussion about reducing BA support significantly, and our main BA grant has been trimmed each year subsequently as we have been prompted to develop more robust, independent funding. By contrast, more recently the BIRI have attracted increasingly positive noises from the British Academy. There is now talk of the BIRI constituting part of the UK's overseas research infrastructure and enabling British influence abroad through the use of 'soft power' and 'science diplomacy'. Others argue that the BIRI offer strategic advantages in a potential post-Brexit world and a future where the UK may have to rethink its international relations and the channels through which it nurtures these. Notwithstanding the political turmoil the UK is experiencing in Autumn 2019, the BA's support for BIRI and their collective future looks brighter than it did in 2016. In turn, the BIRI have responded to this fastchanging landscape by developing closer relations amongst our institutes.

Emerging BIRI cooperation is fuelled in part by the belief that we will address this challenging context more successfully if we work together to exploit our collective potential. This potential, and its growing recognition by external parties, has become 
more apparent as various recent opportunities have come our way. The BIRI have been invited to bid collectively for Independent Research Organisation (IRO) status. This would allow us to bid for government funded research grants in our own right (which we cannot do at present). We have also been invited to work with a Doctoral Training Partnership (the networks of universities that organise and deliver government-funded PhD training provision in various regions around the UK). These opportunities would embed the BIRI's research within the wider circuits of contemporary research funding and provision; they would allow us to operate as contemporary research organisations. Consequently, we have started meeting to organise how we might present a more coherent, unified face to these overtures from potential funders, user-groups and organisations. We plan to produce a BIRI manifesto to this end. From the largest to the smallest BIRI, we realise that cooperation is the way to address future opportunities and to demonstrate to the BA (and to BEIS behind the BA) that we offer a clear return for their investment.

Such is the emerging context for the BIRI and for the SLS. As the smallest of the BIRI we are stronger alongside, and working with, our sibling institutions. Of course there is no guarantee that the particular opportunities that are emerging now will stretch into the future indefinitely; as recently as 2016, as noted, the picture was far gloomier. Yet if we fail to engage we will remain small and fragile, with no full time staff and reliant on volunteers to undertake our key roles voluntarily. If we do chase the opportunity to grow amidst the BIRI, the future of SLS may develop in interesting new ways.

\section{David Atkinson, Chair: The Society for Libyan Studies}

